\title{
Effect of Oxidation Degree on Valence Change and Distribution of Octahedral Fe Element in Biotite
}

\author{
Li Ziqian ${ }^{1}$, Huang Zhiliang ${ }^{1, a}$ and Wei Yu ${ }^{1}$ \\ ${ }^{1}$ School of Material and Engineering, Wuhan Institute of Technology, Wuhan 430074, China
}

\begin{abstract}
In this paper, the valence change and distribution of iron elements in octahedral vacancies of biotite were studied in the oxidation process. The biotite and saturated barium nitrate solution were mixed in dilute hydrochloric acid under hydrothermal reaction conditions, the solid after reaction was used as the test sample. Firstly, the remainder potassium and iron content were measured by atomic absorption spectrometry(AAS). Secondly, the state of iron along with oxidation degree increased was analyzed, in addition, the phase composition and the change of layer spacing in samples was detected by X-ray diffraction(XRD). Thirdly, The variation mode of $\mathrm{Si}-\mathrm{O}$ bond were characterized by Fourier transform infrared spectroscopy(FT-IR).This research was adopted hydrogen ions in diluted hydrochloric acid and nitrate ions in barium nitrate to provide oxidation environment for reaction, and the oxidation degree was controlled by adjusted the amount of hydrogen ion introduced. We found out that the amount of hydrogen ion is positively correlated with oxidation degree in biotite, and the deeper oxidation degree in biotite, the lower electronegativity of singer layer. Potassium and iron element would be release out of micaceous structure during the biotite oxidation. The higher the oxidation degree is, the greater the releasing happen. The charge density combining Fe oxidation and releasing firstly increased then decreased with the oxidation degree turned greater. During the oxidation, the Si-O vibrated would change from parallel layer vibration model to vertical vibration model.
\end{abstract}

\section{Introduction}

Layered silicate is a good template material to prepare organic composite. [1-2] Mica, as an important member of layered silicates, has been attached more and more attention. It is almost inevitable that $\mathrm{Fe}$ element occupies part of octahedral sites in natural mica. And the content and valence of Fe element contribute a responsibility to the charge density of aluminosilicate sheet which is very important to the utilization of mica.

Many papers about oxidation of mica have been published. Some of them are concentrated on the potassium releasing in the view of potassium supplement in soil. [3] Their research about the structure of mica after oxidation is mostly focused on the study of the hydroxyl in mica. [4-5]The research about valence change of Fe element and the distribution of Fe element with different valence at different oxidation degree has not been exposed too much. [6]

\footnotetext{
${ }^{\mathrm{a}}$ Corresponding author : hz16455@126.com
} 
In this paper, the effect of oxidation degree in biotite on potassium located between aluminosilicate sheets and iron element located in octahedral sites was studied, aiming to introduce a sight of the valence change of Fe element and the distribution of Fe element with different valence at different oxidation degree.

\section{Experimental}

\subsection{Reagents and instruments}

The materials used in the research were listed in Table 1:

Table 1. Raw materials

\begin{tabular}{cc}
\hline Name & Remark \\
\hline Biotite & High purity, purchase from Lingshou town of Hebei Province \\
$\mathrm{Ba}\left(\mathrm{NO}_{3}\right)_{2}$ & AR \\
$\mathrm{HCl}$ & AR, diluted to $0.5 \mathrm{~mol} / \mathrm{L}$ \\
$\mathrm{H}_{2} \mathrm{O}$ & Homemade in lab \\
\hline
\end{tabular}

The experiment involved these instruments: CPA1245 analytical balance; DF-101S temperature control magnetic stirring apparatus; HH-S smart thermostat water bath; SHZ-DIII air pump filtration; DZ-2BC drying tunnel.

\subsection{Methods}

Quantitative biotite powder and barium nitrate were weighted accurately into an Erlenmeyer flask. Then different amounts of hydrochloric acid $\left(\mathrm{V}_{\mathrm{HCl}}\right)$ and distilled water $\left(\mathrm{V}_{\mathrm{H} 20}\right)$ were added according to a series of setting solid to liquid ratios. The total volume of the final solution was $100 \mathrm{~mL}$. the untreated raw biotite sample was named as S- 0 . The Erlenmeyer flask was thereafter putted into thermostat water bath at $60^{\circ} \mathrm{C}$ for 5 hours. After that, a filtration was performed immediately. The residue was dried at $90{ }^{\circ} \mathrm{C}$ for 12 hours, then put in a new clean flask. The above steps were repeated 4 times. The final residue was saved for characterization. The final sample were marked as $\mathrm{S}-1$ that the $\mathrm{V}_{\mathrm{HCl}}: \mathrm{V}_{\mathrm{H} 20}$ was $0.0: 100.0, \mathrm{~S}-2$ that the $\mathrm{V}_{\mathrm{HCl}}: \mathrm{V}_{\mathrm{H} 20}$ was $2.0: 98.0, \mathrm{~S}-3$ that $\mathrm{V}_{\mathrm{HCl}}: \mathrm{V}_{\mathrm{H} 20}$ was $4.0: 96.0$, and $\mathrm{S}-4$ that the $\mathrm{V}_{\mathrm{HCl}}: \mathrm{V}_{\mathrm{H} 20}$ was $8.0: 92.0$.

\subsection{Characterization}

Germany Ru-200 X-ray powder diffraction (Cu Target K alpha, 40kV tube voltage, current of 100mA tube, scanning step 0.04 degree per second), Fourier transform infrared spectrometer (Niocolet impact of 420), MS-500 Mossbauer spectrum (testing temperature of $300 \mathrm{~K}$ and testing time of 60 hours)was used to characterize the crystal structure, chemical bonds vibration, and valance of iron element of the final sample, separately.

The content of potassium and iron values in filter residue were determined by atomic absorption spectrometry(AAS).

\section{Results and discussion}


Firstly, we have to explain that the oxidation environment in reaction solutions was supplied by the hydrions in diluted hydrochloric acid combined with the $\mathrm{NO}_{3}{ }^{-}$in barium nitrate. It's obvious that the $\mathrm{NO}_{3}{ }^{-}$in solution is abundant, so we control the degree of oxidation by controlling the amount of hydrochloric acid added.

\subsection{AAS analysis}

The content of potassium and iron values in samples were showed in Table 2.

Table 2. K, Fe content of different samples

\begin{tabular}{cccccc}
\hline Samples & $\mathrm{S}-0$ & $\mathrm{~S}-1$ & $\mathrm{~S}-2$ & $\mathrm{~S}-3$ & $\mathrm{~S}-4$ \\
\hline $\mathrm{V}_{\mathrm{HCl}}: \mathrm{V}_{\mathrm{H} 2 \mathrm{O}}$ & - & $0.0: 100.0$ & $2.0: 98.0$ & $4.0: 96.0$ & $8.0: 92.0$ \\
$\mathrm{~K}(\mathrm{wt} \%)$ & 6.81 & 5.36 & 3.12 & 1.65 & 0.59 \\
$\mathrm{Fe}(\mathrm{wt} \%)$ & 10.34 & 10.21 & 7.68 & 5.52 & 2.18 \\
\hline
\end{tabular}

The $\mathrm{K}$ content of oxidized biotite (S-1, S-2, S-3, and S-4) were gradually declining with the increase of $\mathrm{V}(\mathrm{HCl})$, as well as the $\mathrm{Fe}$ content, as shown in Table 2. This means potassium and iron element were released out of micaceous structure during the oxidation, and the higher the oxidation degree is, the greater the releasing happens.

\subsection{Mossbauer spectral analysis}

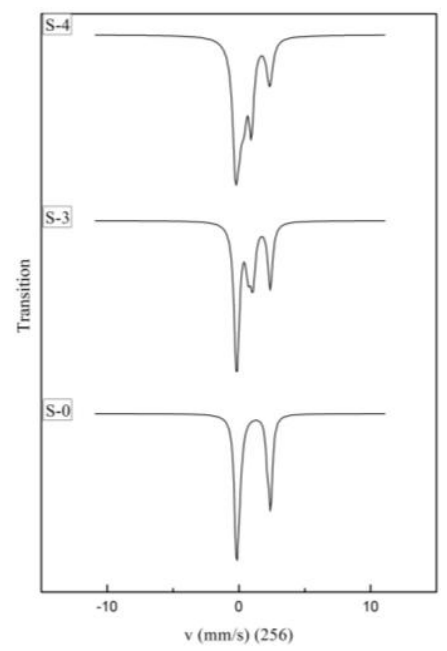

Figure 1. Mossbauer spectrums of S-0, S-3, and S-4

Figure 1 shows the Mossbauer spectrum of S-0, S-3, and S-4. The corresponding data are shown in Table 3. M1 and M2 refer the two kinds of octahedral sites in micaceous structure. As shown in Figure 4-a, if the $\mathrm{OH}$ ions are situated at adjacent corners of an octahedron the site is called M2, whereas if they are at opposite corners the sites called M1. [7]

Table 3. Mossbauer spectrum parameters of S- 0, S-3, and S-4 


\begin{tabular}{|c|c|c|c|c|c|c|c|c|c|c|c|c|c|c|}
\hline \multirow{3}{*}{ Samples } & \multicolumn{7}{|c|}{$\mathrm{Fe}^{2+}$} & \multicolumn{7}{|c|}{$\mathrm{Fe}^{3+}$} \\
\hline & \multicolumn{3}{|c|}{ M2 } & \multicolumn{3}{|c|}{ M1 } & \multirow{2}{*}{$\begin{array}{c}\mathrm{A} \\
(\%)\end{array}$} & \multicolumn{3}{|c|}{ M2 } & \multicolumn{3}{|c|}{ M1 } & \multirow{2}{*}{$\begin{array}{r}\mathrm{A} \\
(\%\end{array}$} \\
\hline & $\begin{array}{c}\text { C.S } \\
(\mathrm{mm} / \mathrm{s})\end{array}$ & $\begin{array}{c}\text { Q.S } \\
(\mathrm{mm} / \mathrm{s})\end{array}$ & $\begin{array}{c}\mathrm{A} \\
(\%)\end{array}$ & $\begin{array}{c}\text { C.S } \\
(\mathrm{mm} / \mathrm{s})\end{array}$ & $\begin{array}{c}\text { Q.S } \\
(\mathrm{mm} / \mathrm{s})\end{array}$ & $\begin{array}{c}\mathrm{A} \\
(\%)\end{array}$ & & $\begin{array}{c}\text { C.S } \\
(\mathrm{mm} / \mathrm{s})\end{array}$ & $\begin{array}{c}\text { Q.S } \\
(\mathrm{mm} / \mathrm{s})\end{array}$ & $\begin{array}{c}\mathrm{A} \\
(\%)\end{array}$ & $\begin{array}{c}\text { C.S } \\
(\mathrm{mm} / \mathrm{s})\end{array}$ & $\begin{array}{c}\text { Q.S } \\
(\mathrm{mm} / \mathrm{s})\end{array}$ & $\begin{array}{c}\mathrm{A} \\
(\%)\end{array}$ & \\
\hline S-0 & 1.12 & 2.56 & 80 & 0.94 & 2.41 & 20 & 73 & & & & 0.01 & 0.12 & 100 & 27 \\
\hline S-3 & 1.08 & 2.59 & 100 & & & & 41 & 0.49 & 1.15 & 57 & 0.26 & 0.9 & 43 & 59 \\
\hline S-4 & 1.37 & 1.93 & 100 & & & & 28 & 0.33 & 1.23 & 55 & -0.03 & 0 & 45 & 72 \\
\hline
\end{tabular}

As shown in Table 3, the content of $\mathrm{Fe}^{3+}$ in S-4 is greater than that in S-3, and both of them are greater than that in $\mathrm{S}-0$. The content of $\mathrm{Fe}^{2+}$ shows a reverse trend. The means that the oxidation degree of biotite increased as the $\mathrm{V}(\mathrm{HCl})$ increased. Furthermore, in $\mathrm{S}-3$ and $\mathrm{S}-4, \mathrm{Fe}^{2+}$ is more likely to occupy in $\mathrm{M} 2$ vacancy and $\mathrm{Fe}^{3+}$ in $\mathrm{M} 1$ vacancy, which demonstrates $\mathrm{Fe}^{2+}$ in $\mathrm{M} 1$ vacancy was prior to been oxidized. The ratio of $\mathrm{Fe}^{3+}$ in $\mathrm{M} 2$ and $\mathrm{M} 1$, which in $\mathrm{S}-3$ is 1.3 and in $\mathrm{S}-4$ is 1.2 , is close, demonstrating the over $\mathrm{Fe}^{3+}$ content in $\mathrm{M} 2$ would be partly released to keep the charge balance.

\subsection{XRD analysis}

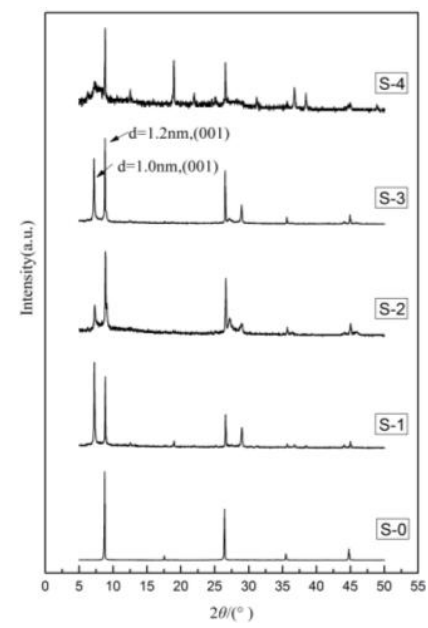

Figure 2. XRD pattern of raw ore and treated biotite

Figure 2 is the XRD patterns of samples. The specific diffraction peaks of mica were clear, meaning the micaceous structure retained during the oxidation. A new peak whose $\mathrm{d}$ value is about $1.2 \mathrm{~nm}$ emerged in oxidized biotite samples (S-1, S-2, S-3, and S-4). This is due to the hydrated barium had occupied part of the potassium site after $\mathrm{Ba}^{2+} / \mathrm{K}^{+}$exchange. [8]

The strength of the new peak went up first then down as oxidation degree turned greater. This is due to the change of charge density of aluminosilicate sheet. At the beginning of the oxidation, the charge increase of $\mathrm{Fe}^{2+}$ was over the charge loss of $\mathrm{Fe}$ releasing. The charge density of the aluminosilicate sheet would go down, weakening the electronical force and resulting in the sheets expanded. As the oxidation stronger, the charge change was reversed, leading to the charge density went up and the sheets shrank.

\subsection{Infrared analysis}




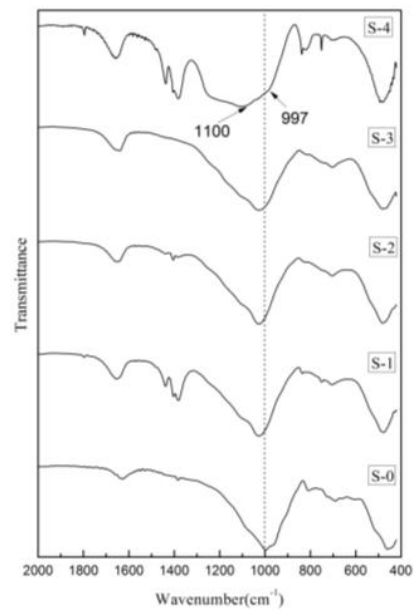

Figure 3. FT-IR spectrogram of raw ore and treated biotite

As showed in Figure 3, the Si-O vibration band which is at $1000 \mathrm{~cm}^{-1}$ around shifted towards high frequency $\left(1100 \mathrm{~cm}^{-1}\right)$. According the infrared spectroscopy study in clay minerals by Farmer V C, the infrared absorption peak with a wave number of $1000 \mathrm{~cm}^{-1}$ belongs to the layer vibration(mode $\mathrm{E}_{1}^{1}$ ), and the infrared absorption peak of $1100 \mathrm{~cm}^{-1}$ belongs to the vertical vibration(mode $A_{1}^{1}$ ) [9]. The frequency of $\mathrm{Si}-\mathrm{O}$ vibration band in vertical vibration $\left(\mathrm{A}_{1}^{1}\right)$ is higher than that in parallel layer vibration $\left(\mathrm{E}_{1}^{1}\right)$, because $\mathrm{Si}-\mathrm{O}$ tetrahedron force field deflects from trigonal symmetry. [10] The symmetry deflects of the silicon tetrahedron structure results in an infrared absorption peak shift that can be demonstrated using the Figure 4-a.

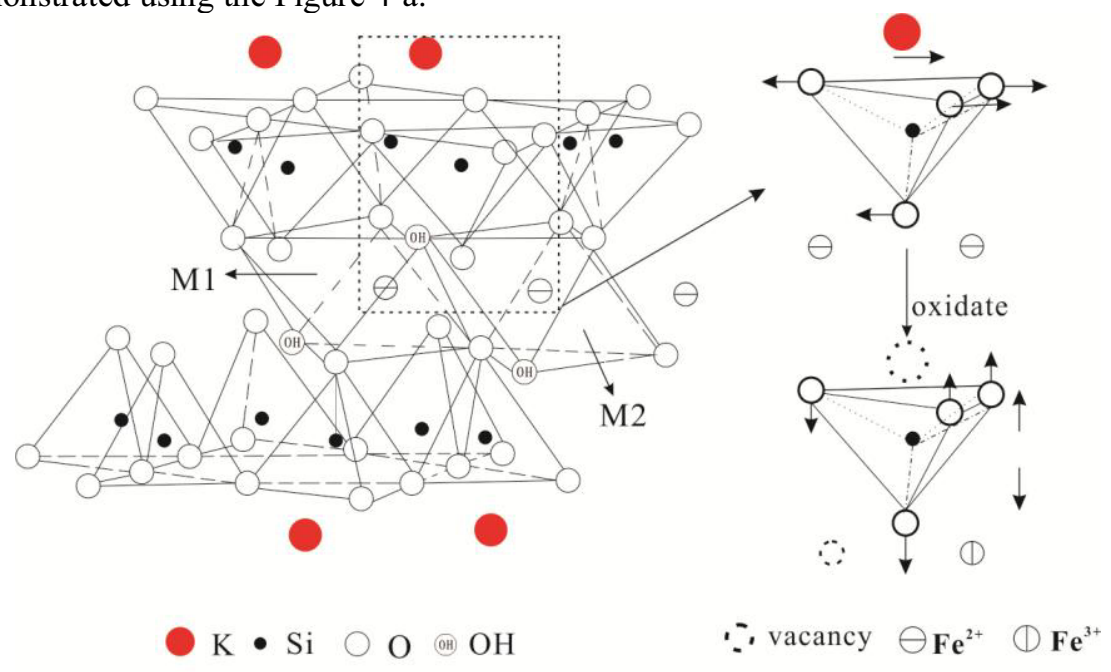

a

$\mathrm{b}$

Figure 4. Diagram of the biotite structure (a), change of Si-O vibration mode after oxidation (b)

We can see the environment of Si-O tetrahedral clearly from Figure 4-a, under $\mathrm{K}^{+}$, upper iron ions. The Figure 4-b show the change of Si-O tetrahedral environment. In original ore (S-0), Si-O vibrates as parallel layer vibration. After oxidized, the octahedron site and potassium site would partly be vacancies, the vacancy defects cause the symmetry of silicon tetrahedron structure deflects, resulting the $\mathrm{Si}-\mathrm{O}$ vibrated as vertical vibration. Therefore, the frequency of $\mathrm{Si}-\mathrm{O}$ vibration band would shift to higher position after oxidized. 


\section{Conclusion}

Potassium and iron element would be release out of micaceous structure during the oxidation. The higher the oxidation degree is, the greater the releasing happens. The new emerged peaks of $1.2 \mathrm{~nm}$ turned stronger then weaker, and back and forth. This is due to the charge density combining Fe oxidation and releasing firstly increased then decreased with the oxidation degree turned greater. Many vacancies left after oxidation and $\mathrm{K} / \mathrm{Ba}$ exchange, resulting in the change of Si-O symmetry. During the oxidation, the Si-O vibrated would change from parallel layer vibration model to vertical vibration model.

\section{Foundation item}

This research is supported by National Natural Science Foundation of China (51374155), Hubei Province Key Technology R\&D Program of China (2014BCB034).

\section{References}

1. Agag T, Taepaisitphongse V, Takeichi T. Reinforcement of polybenzoxazine matrix with organically modified mica[J]. Polymer Composites, 2007, 28(5):680-687.

2. YuMin Chen. Organic modification and intercalation of synthetic fluorine mica with poly(oxyalkylene)-amines[J]. 2004.

3. Kathsutoshi Tomita, Mitsuhiko Dozono. Formation of an interstratified mineral by extraction of potassium from mica with sodium tetraphenylboron. Clays and Clay Minerals, 1972, (2)225-231.

4. Beran A. The occurrence of $\mathrm{OH}$ absorptions in phenakite-an IR spectroscopic study[J]. Mineralogy and Petrology, 1990, 41(2):73-79.

5. Rouxhet P G. Hydroxyl stretching bands in micas: quantitative interpretation.[J]. Clay Minerals, 1970, 8(4):375-388.

6. Rebbert C R, Partin E, Hewitt D A. Synthetic biotite oxidation under hydrothermal conditions[J]. American Mineralogist, 2015, 80(3-4):345-354.

7. Chandra U, Lokanathan S. A Mossbauer study of the effect of heat treatment on biotite micas[J]. Journal of Physics D Applied Physics, 1982, 15(11):2331-2340.

8. Peng Meng, Ziqian Li, et al. Extraction of potassium from Biotite by $\mathrm{Ba}^{2+} / \mathrm{K}^{+}$ion exchange and the structural transformation. Physics and Chemistry of Minerals, 2016 (43), 387-393.

9. Farmer V C. Infrared Spectroscopy in Mineral Chemistry[M]// Physicochemical Methods of Mineral Analysis. 1975:357-388.

10. Lantenois S, Bény $\mathrm{J} \mathrm{M}$, Muller $\mathrm{F}$, et al. Integration of iron in natural and synthetic Al-pyrophyllites: an infrared spectroscopic study. Clay Minerals, 2007, volume 42(1):129-141(13). 